\title{
Assessment of Knowledge, Attitude and Practice of Infection Prevention Among Health Care Providers in Chibombo District Zambia
}

\author{
Evason Mandona ${ }^{1}$, Ebenezer Obi Daniel ${ }^{1, ~}$, Paul Olaiya Abiodun ${ }^{1}$, Israel Olukayode Popoola ${ }^{2}$, \\ Olayinka Victor Ojo ${ }^{1}$, Christie Omolola Adams ${ }^{1}$, Stellamaris Moronkeji ${ }^{1}$ \\ ${ }^{1}$ Department of Public Health, School of Public Health, Texila American University, Georgetown Guyana, South America \\ ${ }^{2}$ Department of Epidemiology and Community Health, Faculty of Medicine, University of Ilorin, Ilorin, Nigeria
}

Email address:

dannypressy@yahoo.com (E. O. Daniel)

${ }^{*}$ Corresponding author

\section{To cite this article:}

Evason Mandona, Ebenezer Obi Daniel, Paul Olaiya Abiodun, Israel Olukayode Popoola, Olayinka Victor Ojo, Christie Omolola Adams, Stellamaris Moronkeji. Assessment of Knowledge, Attitude and Practice of Infection Prevention Among Health Care Providers in Chibombo District Zambia. World Journal of Public Health. Vol. 4, No. 4, 2019, pp. 87-95. doi: 10.11648/j.wjph.20190404.13

Received: October 25, 2019; Accepted: November 22, 2019; Published: December 6, 2019

\begin{abstract}
Hospital or Health facility acquired infections referred to as Nosocomial Infections are health care-associated infections that remain an important Provider/patient safety issue and represent a significant adverse outcome of the health care system. The topic of infection prevention is very important in reducing health costs and the impact of infections among patients in rural health centres. The main objective of this study is to assess the Knowledge Attitude and Practices on prevention of Infection Prevention among health care providers in rural health centres in Chibombo District in Central Province of Zambia. A descriptive cross sectional study of the knowledge, attitude and practice of infection prevention among health care providers in 31 rural health centres of Chibombo district was carried out. Sample size proportional was calculated, and inclusion was done by using simple random sampling in order to make the calculated overall sample size. Data was obtained through structured, self-administered questionnaire. Summated scores were used to grade respondents' knowledge attitudes and practices of Infection Prevention among health care providers in rural health centres in Chibombo District. Data analysis was done using the Statistical package for Social Science (SPSS) version 21, presented using descriptive statistics of frequencies, percentages, pie chart. Inferential statistics of Chi-square was used to test for associations between various factors and the knowledge, attitude and practices of Infection Prevention among health care providers in rural health facilities of Chibombo. A total of 94 $(62.7 \%)$ out of 150 respondents had high level of knowledge while, considerable proportion of 55 (36.7\%) out of 150 respondents had poor knowledge. Almost one-third (26\%) had poor Practice meanwhile all the respondents150 (100\%) had a positive attitude toward infection prevention. There was statistical significant association between profession of health workers, and practice of health care providers towards Infection prevention $(\mathrm{P}<0.05)$. On other hand, there was no significant association between knowledge, practice of Infection Prevention among health care providers in rural health facilities of Chibombo, and age, sex, marital status, religion or duration of work for the respondents $(\mathrm{P}>0.05)$. There is need for the government to consistently provide monthly grant allocation to support in-service training, enforce IP guidelines, purchase of sterilizers, PPEs, increase supervision of IP activities to all rural health facilities in Chibombo district through their committees.
\end{abstract}

Keywords: Infection Prevention, Knowledge, Attitude and Practice

\section{Introduction}

Infection Prevention can be defined as measures practiced by healthcare personnel in healthcare facilities to decrease transmission and acquisition of infectious agents. Infection control measures are based on how an infectious agent is transmitted and include standard, contact, droplet, and 
airborne precautions. Infection in hospitals and other healthcare settings is a problem for health services around the world and major public health problem which is receiving considerable attention and the problems related to this is very serious which causes major health risks that leads to morbidity, mortality and cost. Infection prevention and control measures aim to ensure the protection of those who might be vulnerable to acquiring an infection both in the general community while receiving care due to health problems in the range of settings. Infection control refers to all policies, procedures and activities which aim to prevent or minimize the risk of transmission of infectious disease at health care facilities. It is from the above stated arguments that this study draws influence. The study aims at assessing the knowledge, attitude and practices of health care providers related to hospital acquired infections (HAI) [1-3].

The study Smith R., L., Milliams, C., L. \& Wilkins, 2009 [4] stated that the relationship between health care and infection control was first identified by Florence Nightingale in 1854 during the Crimean war when she served in a military hospital in Scutari in Italy. At that time, the conditions in the hospitals were deplorable. Nightingales observations in Scutari led her to believe that improving hygienic conditions would decrease the number of deaths. Nightingale championed the cause of improved hygiene, food and living conditions for the hospitalized soldiers. She curbed the hospital conditions and called for basic public health, infection control measures, cleanliness, hygiene and education about the importance of the issue. Today health care providers are key players in the fight to ensure the survival of infection control practices.

Infection Prevention is an ancient practice deep-rooted in global cultures. In Africa, Chanda, 2004 [5] stated that the communities protected the health and wellbeing of its members through the practice of Infection Prevention. Traditionally trained surgeons circumcised baby boys aseptically by flaming their equipment over 'chikoloboyi' (open flame lanterns) between circumcisions. This practice aimed at sterilizing instruments thereby preventing infections to the circumcised babies.

The Zambia Infection Prevention Guidelines first edition was developed in 2003 of by the Central Board of Health. The purpose of developing the Infection prevention guidelines was to provide standard guidelines for infection prevention practices applicable at all levels of the health care system in Zambia, which are technically sound and also feasible in the current environment of health care services in Zambia CBoH, 2003 [6]. These basic guidelines such as hand washing with soap and water, and other specific procedures such as sterilization could go a long way in curbing postoperative wound infection in most of our health facilities in Zambia.

Central Board of Health further observed an increase of nosocomial infections rates related to the poor infection prevention practices as unacceptable. For instance, a hospital accreditation survey conducted in 2002 by the Ministry of Health, reported high rates of post-operative infections, showing a post-operative wound infection of $30 \%$ or more among caesarean section patients. In addition, the high rate of attrition, illness and death among health workers are cited as partly contributing to the high risk of infection inherent in the health care professionals when adequate precautions are not taken. Post-operative wound infection prolongs patient hospitalization, leading to increased usage of pharmaceutical services, more laboratory investigations and other services thereby creating an economic burden on the health care system in Zambia. The cost of providing these health services to patients that had been hospitalized longer than expected was an unforeseen cost that resulted in economic burden that deprive the health sector of the much needed resources that could be utilized to provide health services for the hard-toreach population $[6,7]$.

In another study by Elaziz and Bakr 2009 [8], an assessment of KAP of hand washing among HCP Ain Shams University Hospital in Cairo. The knowledge score was higher in nurses compared to doctors (43\% versus $39 \%$ ). Malan (2009), conducted a study to explore and describe the knowledge of registered nurses in two private hospitals in the Nelson Mandela Metropole in South Africa related to infection control and sterile technique principles in the operating room complex. Results showed that $89 \%$ of registered nurses had adequate knowledge on Infection Prevention measures while $11 \%$ did not have [9].

Zambia continues to face high prevalence rates of preventable diseases such as HIV and TB. While considerable success has been made in the health sector, Ministry of Health, 2011-2016, there are imminent public health concerns such as emergence of Multi Drug Resistant TB (MDR-TB), Extremely Drug Resistant TB (XDR-TB), and high TB/HIV co-infection rates. According to recent, World Health Organization 2014, Southern Africa has some of the highest $\mathrm{TB} / \mathrm{HIV}$ co-infection rates in the world, ranging from $50 \%$ to $77 \%$ of the estimated burden. On the other hand, potential risk factors for health care centers or hospitals with a focus on high risk areas such as laboratories include: occupational exposure to TB and $\operatorname{HIV}[10,11]$.

\section{Method}

A cross-sectional descriptive study design was employed in this study. This study was conducted at selected health centres in 31 Chibombo Rural Health Centers respectively. The major health services offered at selected hospitals of interest were Internal Medicine, Gynaecology and Obstetrics, Surgery and Paediatrics. A total of 150 participants (qualified nurses, public health nurses, clinical officers, paramedics, and CHAs) participated in the study. They were recruited through Simple random sampling method into the study.

Data were collected using structured questionnaire consisting of four sections A to D. Section A consists of sociodemographic variables, section $\mathrm{B}$ consists of questions on knowledge of Health care workers on infection prevention; section $\mathrm{C}$ consists of questions on attitude of health care workers towards IP and section D consist of questions on Practice of 
health care workers towards IP. Two research assistants were recruited and trained for the purpose of data collection.

Written permission to conduct the study was obtained from the Medical Superintendent of Chibombo District Health Management Team. The purpose and nature of the study was explained to the study participants. Written informed consent was obtained from the respondents before administering the research instruments. The respondents who agreed to take part in the study were requested to sign a consent form. No participant was coerced and all participants were assured of no harm and that the study was purely for academic purposes. Respondents who declined to participate were reassured that no privileges were to be taken away from them. These respondents were in the usual work environment and hence were not exposed to any physical and emotional danger or harm. Confidentiality and anonymity was maintained in that the respondents' names were not recorded on the questionnaires. Instead numbers were written on the completed questionnaires and these were kept under lock and key.

Data collected were analyzed using SPSS software version 21.0. The data were checked for accuracy and completeness. On completion of data entry, data cleaning was carried out to identify any mistakes that might occur during data entry. Descriptive statistics were used to summarize data into frequencies, graphs and tables. Chi-square was used to test for association between various socio-demographic factors and knowledge and attitude of mothers/guardians.

\section{Results}

One hundred and five (150) questionnaires were distributed for data collection from the health care workers and all one hundred and fifty (150) were fully responded to, and returned. This implies one hundred per cent $(100 \%)$ response rate. The various socio-demographic characteristics of the respondents were shown in table 3. Females formed the largest number of participants $92(61.3 \%)$ while only $58(38.7 \%)$ were between Male. The majority $94(62.7 \%)$ of the respondents were never married, while $97.3 \%$ are Christians. Professional distribution of the respondents revealed that over half $(60 \%)$ are nurses, $10.7 \%$ (16) were paramedics, $10.7 \%$ (16) were Community Health Assistants, 6.0\% (9) were other professionals, 2.7\% (4) were Clinical OfficersPsychaitry, $2.0 \%$ (3) were Clinical officer general, $1.3 \%(2)$ were psychosocial counsellors, $1(0.7 \%)$ was a CDE, and $1(0.7) \%$ was a Doctor. Further, more than half $47.7 \%$ (70) of the respondents had more than 10 year working experience, $26.0 \%$ (39) had less than one year experince, $17.3 \%$ (26) had 1-5 year experince, and 10.0\% (15) worked 6-10 years.

Table 1. DEMOGRAPHIC DATA $(n=150)$.

\begin{tabular}{|c|c|c|}
\hline VARIABLE & FREQUENCY (n) & PERCENTAGE (\%) \\
\hline \multicolumn{3}{|l|}{ SEX } \\
\hline Male & 58 & $38.7 \%$ \\
\hline Female & 92 & $61.3 \%$ \\
\hline TOTAL & 150 & $100 \%$ \\
\hline \multicolumn{3}{|l|}{ AGE } \\
\hline $18-20$ years & 16 & $10.7 \%$ \\
\hline $21-30$ years & 64 & $42.7 \%$ \\
\hline Above 30 years & 70 & $46.7 \%$ \\
\hline TOTAL & 150 & $100 \%$ \\
\hline \multicolumn{3}{|l|}{ MARITAL STATUS } \\
\hline Never Married & 94 & $62.7 \%$ \\
\hline Married & 47 & $31.3 \%$ \\
\hline Widowed & 9 & $6.0 \%$ \\
\hline TOTAL & 150 & $100 \%$ \\
\hline \multicolumn{3}{|l|}{ RELIGION } \\
\hline Christian & 146 & $97.3 \%$ \\
\hline Muslim & 4 & $2.7 \%$ \\
\hline TOTAL & 150 & $100 \%$ \\
\hline \multicolumn{3}{|l|}{ DURATION OF WORK } \\
\hline Less Than 1 Year & 39 & $26.0 \%$ \\
\hline $1-5$ Years & 26 & $17.3 \%$ \\
\hline $6-10$ Years & 15 & $10.0 \%$ \\
\hline More Than 10 Years & 70 & $46.7 .0 \%$ \\
\hline TOTALS & 150 & $100 \%$ \\
\hline \multicolumn{3}{|l|}{ PROFESSION } \\
\hline Doctor & 1 & $0.7 \%$ \\
\hline Nurse & 90 & $60.0 \%$ \\
\hline Psycosocial counsellor & 2 & $1.3 \%$ \\
\hline Clinical OfficerPsychaitry & 4 & $2.7 \%$ \\
\hline Community Health Assistant & 16 & $10.7 \%$ \\
\hline Para Medic & 16 & $10.7 \%$ \\
\hline CDEs & 1 & $0.7 \%$ \\
\hline Public Health Nurse & 8 & 5.3 \\
\hline Clinical officer General & 3 & 2.0 \\
\hline Others & 9 & $6.0 \%$ \\
\hline TOTAL & 150 & $100 \%$ \\
\hline
\end{tabular}


Knowledge of Health care wokers on Infection Prevention

Figure 1 below shows Knowledge Distribution of Respondents on Infection Prevention. More than half 62.7\% (94) out of 150 respondents had high level of knowledge, 36.7\% (55) had moderate knowledge while $0.7 \%(1)$ had low knowledge.

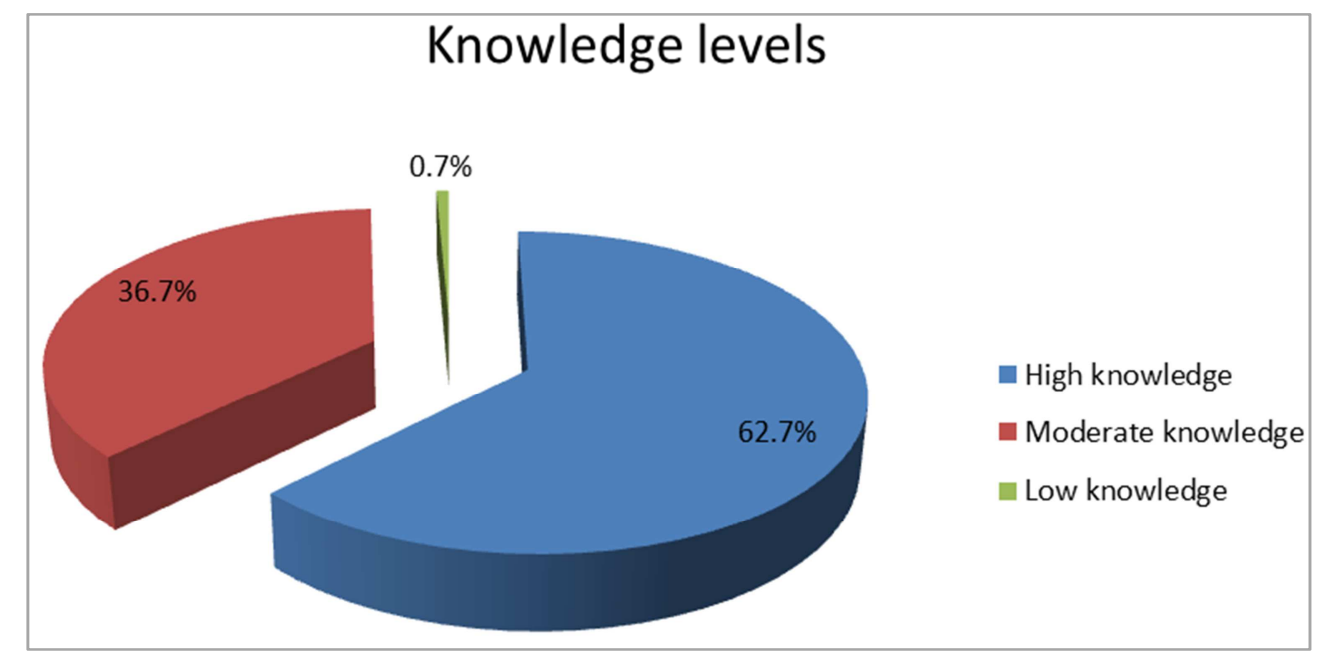

Figure 1. Percentage distribution of Knowlwedge of healthcare wokers towards infection prevention.

ATTITUDE OF HEALTH CARE WORKERS ON INFECTION PREVENTION AND CONTROL

Levels of attitude of health care workers towards infecton prevention is presented in figure two below. All 100\% (150) respondents had positive attitude and none had negative attitude.

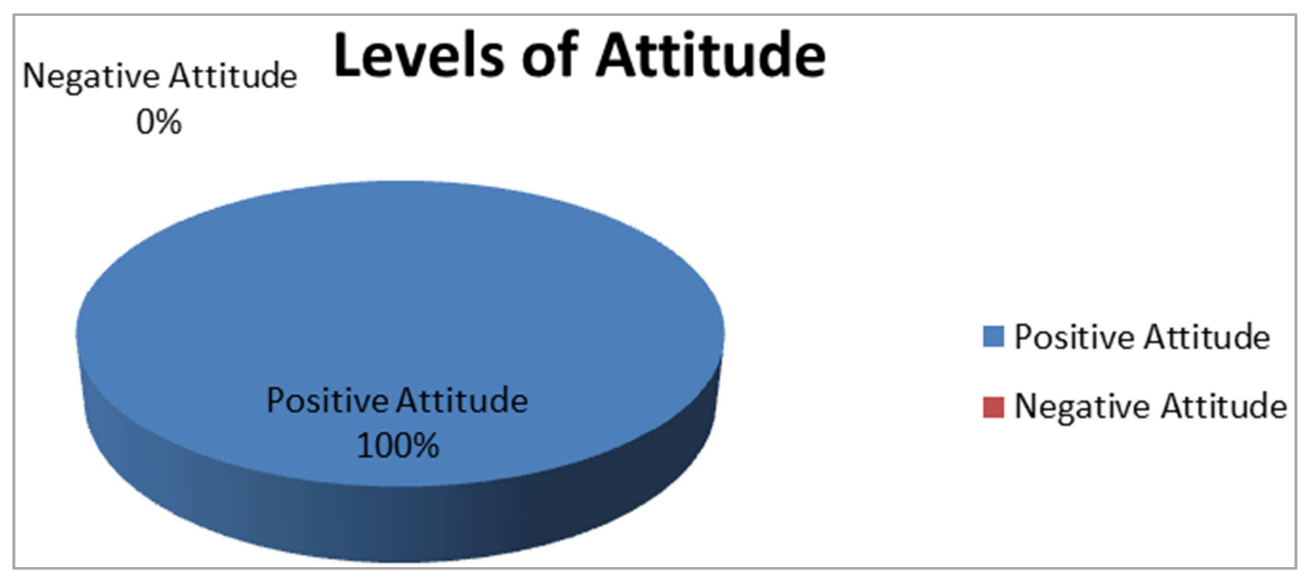

Figure 2. Percentage distribution of attitude of health care workers towards infection prevention.

PRACTICES OF INFECTION PREVENTION AND CONTROL PIE CHART

Figure three belows shows the practice levels of health care wokers on infection prevention in chibombo district. Only 3\% (4) out of 150 respondents had excellent practice, $77 \%$ (116) had good practice and 20\% (30) had poor practice.

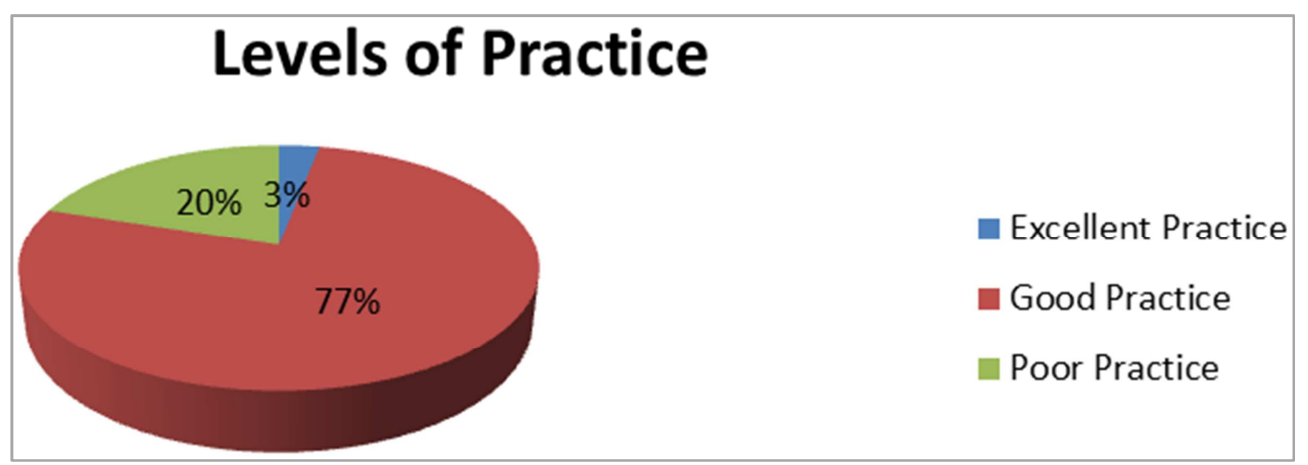

Figure 3. Levels of Practice towards infection prevention pie chart. 
Association between health cares' knowledge and sociodemographic variables

The association between the knowledge and the sociodemographic variables of the respondents is shown in table 2 . There was no statistical significant association between age, sex, marital status, religion, Duration of work, profession, and knowledge of health care workers on Infection Prevention $(\mathrm{P}$ value $>0.05)$

Table 2. Chi-Square analysis showing association between health cares knowledge on infection prevention and socio-demographic characteristics of the respondents.

\begin{tabular}{lll}
\hline & $\chi^{2}$ value & p value \\
\hline Age & 2.243 & 0.055 \\
sex & 3.581 & 0.167 \\
Marital status & 4.484 & 0.313 \\
Religion & 2.448 & 0.294 \\
Duration of work & 7.949 & 0.242 \\
Profession & 15.8883 & 0.601 \\
\hline
\end{tabular}

** Significant at $\mathrm{P}<0.05$

Association between health cares' practice and sociodemographic variables

The association between the practice and the sociodemographic variables of the respondents is shown in table 3. There was statistical significant association between profession of health workers, and practice of health care workers towards Infection prevention $(\mathrm{P}<0.05)$

Table 3. Chi-Square analysis showing association between health cares' practice on infection prevention and socio-demographic characteristics of the respondents.

\begin{tabular}{lll}
\hline & $\boldsymbol{\chi}^{2}$ value & p value \\
\hline Age & 9.236 & 0.055 \\
sex & 4.907 & 0.086 \\
Marital status & 3.623 & 0.459 \\
Religion & 0.89 & 0.957 \\
Duration of work & 8.527 & 0.202 \\
Profession & 65.535 & $0.00^{*}$ \\
\hline
\end{tabular}

** Significant at $\mathrm{P}<0.05$

There was statistical significant association between profession of health workers, and practice of health care workers towards Infection prevention $(\mathrm{P}<0.05)$

\section{Discussion}

\subsection{Socio-demographic Characteristics}

The sample included doctor, nurses, paramedics namely Clinical officers, Nutrition technicians, Pharmarcy technicians, Enviromental Health officers, Community Health assistant (CHAs), Safe Mother Action Groups (SMAGs) CDEs and others like counselors working in Rural Health centres of Chibombo District who work in clinical areas. Majority (46.7\%) of the respondents were aged between Above 30 years (42.7\%) of the respondents were aged between 21 and 30 years, while $10.7 \%$ of the respondents were aged between 18 and 20 years (table 1).
More than half $(61.3 \%)$ of the respondents were females compared to males $(38.7 \%)$. The findings are similar to the study by Nawila (2010) in her study of knowledge, attitude and practice of on hand hygiene by health workers at Kabwe General Hospital where majority $64 \%$ of the respondents were females. Results are also similar to the study of Chitmwango (2017) in his study of knowledge, attitude and practice of Nurses to infection prevention measures at Ndola University Teaching Hospital where $78 \%$ of the respondents in the study were female. This could be attributed to the fact that, health profession is mostly females dorminaty especially Nursing which was viewed as a feminine career globally. The other reason could be that more females are employed in rural health centres as compared to males health care providers because of their pasion for the job. More than half $(62.7 \%)$ of the respondents were Never married, $31.3 \%$ were married, $6.0 \%$ were widoweds. This signifies the strong entrenched Zambian culture among HCP that regards marriage. This also shows that it is accepted as normal in Zambian society.

A higher percentage of the respondents (97.3\%) were Christians because Zambia is predominantly a Christian Nation, as evident from this study conducted, only $2.7 \%$ of the respondents were Muslims.

Majority (46.7\%) of the respondents had more than 10 years working experience, $26 \%$ had less than 1 year experience, $17.3 \%$ had $1-5$ years working experince and $15 \%$ had only worked for 6-10. Majority of respondents were in the category of those that had served for more than 10 years because during this period most of the HCP are settled in employment and there are very few who may like to get transferred out or resign to go for greener pastures.

The research findings revealed that $60 \%$ were nurses being the majoriy of the respondents in thisstudy. $10.7 \%$ were paramedics consisting of the same proportion as the the community health assistants (10.7\%), 5.3\% were Public Health Nurses, while only 1 Doctor reprenting $0.7 \%$ participated in this study. $6.0 \%$ were others which included counsellors. The proportion of HCPs is in line with staff establishment which has seen an increase in the number of Nurses being employed in health institutions as compared to other disciplines. This could be due to the fact that more nurses are trained each year as there are many nursing schools.

\subsection{Knowledge of Health Care Wokers About Infection Prevention}

A study of similar nature conducted by Alemayehu, Ahmed and Sada, 2016 in Ethiopia revealed 95.19\% of Health care providers had good knowledge and $4.81 \%$ were knowledgeable poor about Infection prevention. These results could be high when compared with finding from Bahirdar City which revealed that $84.2 \%$ of the Health care providers were knowledgeable. According to Concise English Dictionary 2006, Knowledge is information understanding and skills acquired through experience or education and is 
one of the factors that contribute to the HCPs' practice towards Infection Prevention measures. Adequate knowledge about infection prevention is important because it helps the HCPs to reduce chances of contracting or spreading infections to others. This is in line with Katowa 2007. This study revealed that most respondents had high knowledge $(62.7 \%)$ while $36.7 \%$ had moderate knowledge. (See figure $1)$. With regards to knowledge levels, this study showed that among the respondents $45.7 \%$ of them who are within ages 21-30 had high knowledge towards infection prevention while $38.2 \%$ within the same age has Moderate knowledge towards Infection Prevention, 57.4\% of the respondents who were Female had high knowledge while $69.1 \%$ had moderate knowledge, $68.1 \%$ of the respondent are never married and they had good knowledge on Infection Prevention, Total of $95.7 \%$ of the respondents who were Christians had high knowledge on infection Prevention while $4.3 \%$ who were Muslims had high knowledge, $28 \%$ of those that worked for less than 1 year had high knowledge on infection Prevention while $20.0 \%$ in the same duration of work had moderate knowledge, and $1(100 \%)$ had low knowledge, $64.9 \%$ of the respondents who were Psychosocial counselors had high Knowledge on Infection Prevention while $1.8 \%$ within the same Profession had Moderate knowledge. There was no significant (see Table 2) association between marital status, Sex, Religion, Duration of work, Profession and knowledge of health care workers on Infection Prevention. The study revealed that there was no significant association between age, sex, marital status, religion, Duration of work, and knowledge of health care workers on Infection Prevention ( $\mathrm{P}$ value $>0.055)$. There was statistical significant association between profession of health workers, and knowledge of health care workers towards Infection prevention [12-14].

The study findings revealed above on knowledge of health care workers on infection prevention are supported by Kelemua $G$ et al 2014 in a study on health care workers knowledge, attitude and practice that was done on infection prevention and associated factors in the health institution. The majority, $99.3 \%$ of health care workers had good knowledge. This study finding is high when compared with our study as well as finding from Bahirdar City, Gulilat, K. \& Tiruneh, G in 2014 which assessed knowledge, attitude and practice of health care workers on infection prevention in health institution. The study revealed that $84.2 \%$ of the Health care providers were knowledgeable. This discrepancy may be due to sample size, study setting and characteristics of study participants and availability of training program. This is also in line with the study conducted by Alemayehu, Ahmed and Sada, 2016 in Ethiopia which showed that $95.19 \%$ of Health care providers had good knowledge and $4.81 \%$ had poor knowledge about Infection prevention. Hussen SH et al 2017, also support the above findings which show that majority of health care workers' knowledge and attitude toward infection prevention in Wolaitta Sodo Otona teaching and referral hospital were good. Desta et al 2018 also support the above findings which shows that majority of the respondents has good knowledge towards infection prevention while minority of the respondent has poor knowledge towards infection prevention [12, 15, 16-18].

\subsection{Attitude Towards Infection Prevention}

From the study, all $100 \%$ respondents had positive attitude towards infection prevention measures and none had negative attitude (see figure 2). The findings were in line with the study by Nawila 2010 on knowledge, attitude and practice of hand hygiene by health workers at Kabwe General Hospital where most of the respondents, $98 \%$ had positive attitude towards IP. In addition, findings are similar to that of Katowa 2007 and Mulembwe 2012 results revealed that majority of the respondents had positive attitude towards IP. The reason could be that the respondent answered what they know academically and not what they felt or did or it could be that the attitude was truly positive. The findings, however were different with that of Munganga in 2007 in which $74 \%$ of the respondents had a negative attitude towards infection prevention. This could be due to the fact that doctors only stay with patients for a shorter period of time than other HCP like nurses. This study showed that HCP were improving their attitude towards IP as currenty study had proven this trend [14, 19-21].

\subsection{Practice on Infection Prevention}

This study revealed that $72 \%$ of the respondents had good practice, $2.0 \%$ had excellent practice while $26 \%$ had poor practice (see figure 3). Among the respondents, $46.3 \%$ of them who are within ages $21-30$ had good Practice towards infection prevention, while $28.2 \%$ within the same age had poor practice towards Infection Prevention, 3 (100\%) who had excellent practice were male, $620 \%$ of the respondents who were Female had good practice while $64.1 \%$ of the same sex had poor practice, $63.9 \%$ of the respondent are never married and they had good practice on Infection Prevention, Total of $97.2 \%$ of the respondents who were Christians had good practice on infection Prevention while $2.8 \%$ who were Muslims had good practice, $26.9 \%$ of those that worked for less than 1 year had good practice on infection Prevention while $23.1 \%$ in the same duration of work had poor practice and only $1(33.3 \%)$ with the same duration of work had excellent practice, $66.7 \%$ of the respondents who were nurses had excellent practice on Infection Prevention while 48.7\% within the same Profession had poor Practice. There was no significant association between age, sex, marital status, Religion, Duration of work of health workers, and Practice of health care workers on Infection Prevention. ( $\mathrm{P}>0.05)$. There was statistical significant association between profession of health workers, and knowledge of health care workers towards Infection prevention.

This study revealed overall good practice by health care practioners and health care institutions with $77 \%$, however, a good $20 \%$ revealed poor practices which need address. Only $3 \%$ represented excellent practice of the health care practioners.

The research found that $76.7 \%$ out of 108 respondents who 
had good practice were nurses, $16.3 \%$ were paramedics, and $6.8 \%$ were CDEs and others while $3.4 \%$ were doctors.

Reeves and Geeddes in 1982 stated that, there is need for experience in carrying out effective hygienic practices. The findings support the hypotheses which indicate that the more experience health care providers have the better the IP practice. This study findings relates to the study done by Pettit in 2001 [22, 23] on health care workers in Egypt who stated that the average compliance to hand hygiene recommendations varied among professional categories of health-care workers. The findings can be attributed to the fact that nurses were the majority participants in the study.

The study revealed that $68.6 \%$ out of 70 respondents with 10 years and above working experience had good practice and $31.4 \%$ out 71 respondents with the same work experience had poor IP Practice. There was no respondent with excellent practice with work experience ranging from 610 years. This is in line with Munganga 2007 who stated that $75 \%$ of doctors with good practice had 10 years experience. Hussen SH et al $2017[17,21]$ also support the above findings which show that majority of health care workers' knowledge and attitude toward infection prevention in Wolaitta Sodo Otona teaching and referral hospital were good and safe enough, but practice of health care workers towards infection control were not sufficient enough.

This study reveals that statistically the age, sex, marital status, religion and duration of work of health care providers in rural health facilities of Chibombo has no significant association with the knowledge and practice of health care workers towards Infection prevention ( $p$ value $>0.05$ ). There was statistical significant association between profession of health workers, and practice of health care workers towards Infection prevention. However, there was no statistical significant association between knowledge of health care providers and profession of health care workers. The above result is supported by Desta et al in 2018 [18] in a study on Knowledge, practice and associated factors of infection prevention among health care workers in Debre Markos referral hospital, Northwest Ethiopia.

\subsection{Significance to Nursing}

The findings of the study have several implications to the objectives of the study. According to the findings obtained, about $62.7 \%$ of the study participants had high level of knowledge, $100 \%$ had positive attitude and $72 \%$ had good IP practice. This has shown that the level of knowledge has a greater influence on both attitude and practice of HCP towards IP. The findings have alot of implications on the health care systems or different components in health practice, research, education and administration under which the discussion is based.

\subsubsection{Nursing Practice}

Health care providers play a critical role in the prevention of health facility acquired infection as their practice may either improve or worsen the infection prevention situation in all health institutions. It is, for this reason, that the district health management should strengthen IP programmes in minimizing the risks of infection transmission in health care setting. The Health facility supervisors should ensure that all health care providers follow the IP standard prcecautions.

The study revealed that, despite good IP practice, there are alot of constraints like inadequate funding /resources, lack of supervision and shortage of manpower. More also, adequate and effective implementation of practice of infection prevention depends on support from the district management for support through the provision of funding, resources, trainings, serminars / workshops and good staffing. Health care providers need to be encouraged on the need to adhere to IP guidelines which should contribute to their good practice and consequently reduce the risk of health facility acquired infection.

Similarly, the IP committee should facilitate in-service trainings for all health care providers in order to build their knowledge base in IP. This will improve their application of theoretical knowledge to their IP practice.

\subsubsection{Research}

Even though standard precautions for infection prevention practices have been published with an evidence-based guideline, there are no standardized methods or tools for measuring adherence of these guidelines. Many rural health facilities rarely carry out routine IP investigations to identify the levels of infection rates and only do so when there is a crisis like an outbreak of wound infections in the institution. It is, therefore, important that further research is conducted at local level and results published through district health clinical meetings. This will provide the understanding of the IP guidelines by the HCP relevant as they will be able to relate research findings to the published guidelines.

\subsubsection{Education}

More than half $(67 \%)$ of the respondents had high levels of knowledge and all the participants $(100 \%)$ had positive attitude. This signifies that HCP are knowledgeable and their attitude is good but the practice poses a big challenge. This implies that a lot has to be done in order to have HCP with adequate knowledge and positive attitude be able to practice IP measures effectively. There is need to continue in- service training in IP for all health care providers. In clinical areas the in- charges and departmental heads should make every effort to ensure that infection prevention guidelines are followed by all health care providers. Only Healthprofessionals educators with certificates in IP should be allowed to teach it in all learning institutions. This certificate is very essential as the educators will teach the course in IP with the passion, knowledge, skill and attitude that the course deserves. These attributes will be transmitted to the learners, who will keep the light shining in their IP practices.

Since HCP are knowledgeable and have positive attitude, they should act as role models to others by putting their knowledge into good practice of infection prevention. This will help in reducing the rates of HAI in the health care settings. The major problem requiring greater reinforcement is provision of resources. In many rural health centres, staff lack resources and 
this contributes to short works, low morale and poor standard practice of IP. Poor staff fulfillment and underpinning of theoretical knowledge about infection control procedures in clinical practice drives the need for targeted education.

\subsubsection{Administration}

For IP programmes to succeed there is need for total financial support from management in terms of resource provision. Management should be able to allocate resources to the IP department ensure that all health care providers have adeqaute materials for practicing IP measures.

Management supports the implementation of IP guidelines and make IP a priority so that the workers can comply with the guidelines. Management support should involve all HCP in coming up with guidelines and protocols for infection prevention. In a situation where the guidelines are already formulated, all HCP should be oriented to the new procedures and protocols as a way of imparting a sense of ownership. This may result in improved practice of IP compared to a situation where management formulated the guidelines and expect HCP to implement.

Infection prevention commodities and supplies like protective materials and disinfectants should consistently be made available to avoid short falls which could lead to compromising of IP standards.

A cost centre for IP should be created for IP in the institution. In addition, a secretariat to oversee the IP activities should be made or formed and put a trained personnel in IP to be in charge.

\subsection{Conclusion}

The study was conducted to determine the knowledge, attitude and practice of infection prevention measures among health care providers in Rural Health centres of Chibombo District. Data was collected from one hundred and fifty (150) respondents who were HCP using a non experimental self administered questionnaire.

The findings from the study showed that, the respondents had high level of knowledge and positive attitude towards infection prevention. The level of practice ranged from poor to good going by the majority of the respondents. The rural health facility IP committees rarely exist and have a big challenge in ensuring that HCP adhere to infection prevention guidelines in order to reduce the rates of nosocomial infection. The district health managements team and IP committees should be conducting spot checks in health centres in order to ensure that IP guide lines are strictly followed. In service training should be a contiuation from trains in order to maintain the highest level of knowledge. This can be done through regular holding of clinical meeting on IP, workshops and seminars.

\subsection{Recommendations}

\subsubsection{To the Government}

The government should consider increasing grant allocation to rural health centres for IP activities. In addition, the government should play a major role in providing and supervising of rural health facilities to ensure that they have IP equipment and facilities like sterilizers, autoclave machines, incinerators, waste disposal pits, adequate running water, elbowoperated taps, sinks for hand washing and ideal sluice rooms for instrument processing and bed pan washers are provided.

The Government through Provincial Offices should supervise these health facilities during the performance assessment to ensure that all health care settings are adhering to the National Policies on infection Prevention. In addition, the Ministry of Health should facilitate holding of in-service short trainings, workshops on IP by lobbying from Non Governmental Organizations and co-operating partners. The $\mathrm{MoH}$ should consider introducing an establishment for IP officer who are being trained by the The University of Zambia to fill up the position to be supervising in all health care facilities in the district. The results of this study suggest the need for a bigger study to cover all the health care facilities in Zambia.

\subsubsection{To Chibombo District Health Managements}

The findings of the study (see table 4) revealed that there is need for Chibombo District Health office to conduct trainings in IP for health care providers. This can be done through the In-service serminars or workshops in order to acquaint the HCP with the knowledge in infection prevention in order delivery of quality health care to communities. There should be equity of access to refresher courses without segregating some category of health care providers like CDEs are usually neglected meanwhile there are also affected.

Health facility policy on IP need to be formulated and made available to IP committees to ensure that all HCP have guidelines to follow in order to improve and enhance the implementation of infection prevention guidelines.

Chibombo District Health office should also ensure that health care providers are provided with adequate IP supplies for them to effectively implement infection prevention activities in there respective health centres.

\subsubsection{To the Infection Prevention Committee}

Infection Prevention Committees should comprise of members from different disciplines in the health care facilities set up and not in-charges alone who are at times committed with administrative. For example, the suggestion that the IP committee should be headed by the In-charge or Enviromental Health officers who prays a critical role in IP activities because of the schedule of the officer.

The IP committee should be empowered to investigate and report to District Health office any members of staff who contravenes the IP guidelines. In addition, the IP committees should formulate and once in a while review local IP guidelines to suit the prevailing situation.

\subsection{Dissemination of Findings}

Dissemination of findings entails the measures that would be undertaken to make information known to the relevant authorities and study subjects on what the study has 
measured. A copy of the research report will be given to the Hospital Management, the District Health office and the Provincial Health Offices of the. A clinical meeting will be organized to meet all health centre in- charges from 31 rural health centres and $\mathrm{CDHO}$.

A copy of the findings will also be sent to the interested parties such as the General Nursing Council of Zambia (GNC), Health Professional Council Zambia (HPCZ) and the Ministry of Health (MoH) who are the policy makers to improve infection prevention practice in the health care facilities. The Texila American University will also be given a copy through the School of Public Health and another copy will be given to Mwachisompola School of Public Health Nursing.

\section{References}

[1] World Health Organization. (2018). Definition of Infection Prevention. http://www.google.com.tr/search.hl=tr\&ir.

[2] Petal, L. (1997). Infection Prevention Guidelines. Infection Prevention with Limited Resource, Chicago.

[3] World Health Organization. (2012). Infection Control. http://www.who.int/tropical/infectioncontrol/en Retrieved $(21 / 01 / 12)$.

[4] Smith R., L., Milliams, C., L. \& Wilkins. (2009). Would Infection after Elective Colorectal Resection. http://www.ncbi.nlm.nih.gov/pmc/article/PMC1356267/

(Retrieved 11 th May, 2009).

[5] Chanda D. O, (2004), An Infection Prevention Manual for Community and Health Care Institutions in Developing Countries, Maidens Publishing Company, Lusaka.

[6] Central Board of Health. (2003). Zambia Infetion Prevention Guidelines. Lusaka: Lusaka.

[7] Mukwato KP, Ngoma CM, Maimbolwa M (2008) Compliance with infection prevention guidelines by health care workers at Ronald ross general hospital Mufulira district. Med J Zambia 35 .

[8] Elaziz A. and Bark I. M. (2009), Assessement of Knowledge, Attitude and Practice of hand Washing Among Health Care Workersin Ain Shams University Hospital in Cairo, Journal of Preventive Medicine, Volume 50, number 1; 19-25.

[9] Malan K, (2009) Registered Nurses' Knowledge of infection control and sterile Technique Principles in the Operating Room Complex of Private Hospitals. Nelson Mandela Metropolitan University

[10] Ministry of Health. (2011-2016). National Health Strategic Plan. Lusaka: Lusaka.

[11] World Health Organization. (2014). Safe Management of Waste from Health-Care Activities.
[12] Alemayehu R, Ahmed K, Sada O (2016) Assessment of Knowledge and Practice on Infection Prevention among Health Care Workers at Dessie Referral Hospital, Amhara Region, South Wollo Zone, North East Ethiopia. J Community Med Health Educ 6: 487. doi: 10.4172/2161-0711.1000487.

[13] Concise oxford English Dictionary (2006) English for general reference and academic study, 11th Edition revised Oxford University Press, Inc.

[14] Mukwato KP, Ngoma CM, Maimbolwa M et al (2007). Compliance With Infection Prevention Guidelines By Health Care Workers At Ronald Ross General Hospital, Medical Journal 35 Of Zambia.

[15] Kelemua G, Gebeyaw T (2014) Assessment of knowledge, attitude and practice of health care workers on infection prevention in Health Institute Bahir Dar City Administration. Sci J Public Health 2: 384-393.

[16] Gulilat, K. \& Tiruneh, G. (2014). Assessment of knowledge, Attitude and Practice of Health Care Workers on Infection Prevention in Health Institution Bahir Dar City Administration. Science Journal of Public Health, pp. Vol. 2, No. 5, 384-393.

[17] Hussen SH et al (2017). Knowledge and Attitude toward Infection Prevention among health care workers' in Wolaitta Sodo Otona teaching and referral hospital, Northwest Ethiopia.

[18] Desta M., Ayenew, T., Sitotaw N., Tegegne, N., Dires M. \& Getie M.. (2018). Knowledge, practice and associated factors of infection prevention among healthcare workers in Debre Markos referral hospital, Northwest Ethiopia. Markos: Debre.

[19] Nawila. M (2010), Knowledge Attitude and Practice of Hand Hygiene by Health Workers at Kabwe General Hospital, Kabwe, Zambia.

[20] Mulembwe (2012), A study to assess the adherence of nurses to Infection Prevention guidelines at Mansa General Hospital, Mansa, Zambia.

[21] Munganga J. K (2007), A Study to Determining the Knowledge, Attitude and Practice of Medical Doctors on Infection Prevention at Kitwe Central Hospital, Kitwe, Zambia.

[22] Reeves and Geeddes (1982). A Study to determine an effective hygienic practices among experience health care providers have the better the IP practice.

[23] Pittet. D and Boyce J. M. (2001), Improving Adherence To Hand Hygiene Practice; A Multidisciplinary approach. Emerging Infectious Diseases, Volume7, No' 2 Retrieved From; Http://Www.Cdc.Gov/Ncidod/Ed/Vol7no'2 Pittet.Htm.

[24] Pittet D, Nejad S. P, Allegranzi B, Syed S. B and Ellis B (2011) Health Care Associated infection in Africa: Geneva, Switzerland. 